\title{
Study of the Effect of Weathering in Natural Environment on Polypropylene and Its Composites: Morphological and Mechanical Properties
}

\author{
Mashael Al-Shabanat \\ Princess Nora Bint Abdurrahman University, Science College - Chemistry Department \\ Riyadh, Saudi Arabia \\ E-mail: ma.naif@hotmail.com
}

\begin{abstract}
Three kinds of samples of PP, first was pure PP, second was PP with the basic stabilization and third with the talc as inorganic filler. The samples were produced using injection molding. The stability of prepared samples in natural weathering condition of Riyadh, in Saudi Arabia was studied. FT-IR and SEM were used to analyze the structural change. Stress at break, elongation at break and young's modulus measured as mechanical properties. However, talc was found to be able to stabilize PP a little.
\end{abstract}

Keywords: Polypropylene, Natural weathering, Exposure, Photo oxidation

\section{Introduction}

Polypropylene is widely applicable polymer material because of having many kinds of advantage such as easy processability and low production cost (Azuma et al. 2009). The composite with mineral has been considered a useful way to improve some properties. Polypropylene / talc composite has been widely studied by many researchers (Dence et al. 2005, Obata et al. 2001, Naiki et al. 2001 ) and has been extensively used as applicable materials for automotive, electric and other industrial components. Most automotives parts would be exposed to natural weathering like heat, humidity, rain, sunshine and atmospheric pollutants such as sand, dust and hydrocarbons, all of this weather factors can be responsible for severe damage. Weatherability is one of important properties for industrial materials (Azuma et al. 2009). Although the wavelength of the sunshine at the earth's surface is over 290nm, the sunshine is enough to initial the degradation (Al-Madfa et al. 1998). The degradation of Polypropylene and its composites have been studied by many researchers. Abu-Sharkh \& Hamid 2003, prepared composites of polypropylene (PP) from date and UV stabilizers. They investigated the stability of the composites in natural weathering conditions of Saudi Arabia and in accelerated weathering conditions. The composites were found to be much more stable than PP under the severe natural weathering conditions of Saudi Arabia and in accelerated weathering trials. Compatibilized samples were generally less stable than uncompatibilized ones as a result of the lower stability of the maleated polypropylene. Irgastab and Tinuvin are found to be efficient stabilizers for $\mathrm{PP} /$ cellulose fibre composites. In addition to enhanced stability imparted by the presence of the fibres in the composites, enhanced interfacial adhesion resulting from oxidation of the polymer matrix can be the source of retention of mechanical strength.

Xue et al. 2007, developed aspen fiber-polypropylene composites (APC). The mechanical properties of APCs with five different fiber-loadings were evaluated at the room temperature, $4{ }^{\circ} \mathrm{C}$, and $40^{\circ} \mathrm{C}$. Environmental effects on the mechanical properties of APCS were experimentally quantified after conditioning the APCs with two different fiber-loadings in the following temperature and humidity for over $7000 \mathrm{~h}$ : (1) hot/dry at $40{ }^{\circ} \mathrm{C}$ and $30 \%$ relative humidity (RH), (2) hot/wet at $40{ }^{\circ} \mathrm{C}$ and $82 \% \mathrm{RH}$, (3) cold/dry at $4{ }^{\circ} \mathrm{C}$ and $30 \% \mathrm{RH}$, and (4) cold/wet at $4{ }^{\circ} \mathrm{C}$ and $82 \% \mathrm{RH}$. The tensile moduli, flexural moduli, and the flexural strength increased as the woodfiber content increased in the composites. The tensile strength decreased as the fiber content increased. The tensile strength was shown to slightly improve with an addition of a coupling agent between the aspen fibers and polypropylene. The simple empirical micromechanics Halpin-Tsai model for randomly distributed short fiber reinforced composites was employed to predict the homogenized elastic moduli of APC, by optimizing the interfacial model parameter. Scanning electron microscopy (SEM) micrographs confirmed that an addition of the adhesion promoter maleated anhydride polypropylene (MAPP) between the aspen fibers and polymeric matrix improved the interfacial bonding.

The effect of talc as a filler on degradation of polyolefin has been studied. Yang et al. 2005, focused on the natural photo-oxidation of HDPE composites, with several inorganic fillers. Among them, talc as inorganic filler. Fourier transform spectroscopy (FTIR), ultraviolet spectroscopy (UV), scanning electron microscopy (SEM) and pyrolysis 
gas chromatography-mass spectroscopy (PGC-MS) were used to analyse the structural changes, the reflection and absorbance of ultraviolet light, the surface morphologies and the volatile oxidation products of samples during natural aging. After 180 days of exposure, the results showed that some inorganic filler, e.g., $\mathrm{CaCO}_{3}$ and wollastonite, can stabilize HDPE a little. In HDPEs filled with these fillers lower degrees of degradation were observed. In contrast, other inorganic fillers more or less accelerated the photo-oxidation degradation. They are act as photo-oxidation catalysts with the rank of kaolin $>$ diatomite $>$ mica $>$ black mica $>$ talc. Inorganic fillers also have some effects on the crystallinity of HDPE after photo-oxidation. The surfaces of the composites after exposure became rough and with cracks, but showed different damage patterns. A seriously damaged surface did not definitely correspond to a great oxidation degree. The remaining volatile oxidation products of the photo-oxidised composites were proven to be mostly a series of $n$-alkanes. A hypothesis was proposed that the relative absorbances to UV light in $290-400 \mathrm{~nm}$ by these fillers are the key factors influencing the photo-oxidation.

In other study of Azuma et al. 2009, the comparisons of degradation behavior of polypropylene(PP) and PP/talc composites were carried out with one outdoor weathering test at Hidaka, Saitama, Japan and three accelerated weathering (xenon, metal halide and carbon arc lamps) tests, respectively. The outdoor exposure vigorously advanced these degradations with the lowest amount of UV exposure energy. It was found that the degradation rates were affected by the visible light intensity in the light sources. In the case of the existence of talc compound, the degradation was synergistically accelerated by the exposures of the sunshine, the xenon and the metal halide lamps having higher visible light intensities. In addition, the degradations of the PP and the PP/talc composites were found to be synergistically accelerated by sunlight exposure and the acid rain, too. Leong et al. 2004, prepared two kinds of composites, namely single-filler polypropylene (PP) composites (containing either talc or calcium carbonate) and hybrid-filler PP composites (consist of a mixture of talc and calcium carbonate). These specimens were subjected to natural weathering i.e. tropical climate in Penang, Malaysia for 6 months. After 6 months of exposure, the mechanical properties of single-filler PP composites deteriorated due to severe physical and chemical degradation. However, the hybrid-filler PP composites were found to show better retention in mechanical properties albeit having undergone some degree of surface-degradation as well. It is believed that in hybrid composites, the interparticle cavities, created by low interaction between $\mathrm{CaCO} 3$ fillers and the matrix, would dampen crack propagation from the surface to the interior of the samples, thus minimizing internal damage. Talc particles in the inner parts of the specimen would in turn act as the main reinforcement, which explains the retaining of mechanical properties in hybrid composites.

In this study, the degradation and stabilization of PP, PP/the basic stabilization and $\mathrm{PP} /$ talc composites under natural weathering of Riyadh city in Saudi Arabia will be investigated by studding the morphology and the mechanical properties.

\section{Experimental}

\subsection{Materials and Preparation}

The Polypropylene used was supplied by Saudi Basic Industries Corporation (SABIC). The brand name for it is PP520L. It is homo polymer and the details of it are given in Table 1. The additives used in a composite were the basic stabilization and talc (Luzenac, France). The surface of talc had not been subjected to any chemical treatment. The prepared samples in this study are three. The first, polypropylene without any additives. The second, polypropylene with basic stabilization and the third, talc filled polypropylene $(10 \%)$. The samples are denoted as (PP, PPW and TPP) respectively. Injection molding was carried out using a Battenfeld BSKN 400/100HK KS, Germany. The molding conditions are listed in Table 2.

\subsection{Exposure Procedure}

The samples were exposed to natural weathering (all environmental effects such as rain, sunlight, wind etc.) at Riyadh city in Saudi Arabia. The natural exposure was conducted for a period of 6 months from April to September 2009, the details of climate condition of Riyadh city in this period is given in Table 3 [Online]. The specimens were attached to a rack with a rack holder and were placed on the roof of our research building. Samples were collected every 2 months to study of the effect of weathering .

\subsection{Characterization}

Fourier transform infra-red (FTIR) analysis were done for weathered and unweathered samples in the wavenumber range of 4000-400 $\mathrm{cm}^{-1}$ to gives out the indication of formation of the oxidation products by using Fourier-transform infrared (FTIR) spectroscopy (Thermo Nicolet, FT-IR Nexus). Scanning electron microscopy (SEM) on the surface of specimens before and after the exposure were carried out to study effect of natural weathering on structure and morphology by using Jeol JSM-6360LV Scanning Electron Microscope. 


\subsection{Mechanical Testing}

Tensile properties, elongation at break, tensile stress at break and young's modulus were measured using an Instron corporation machine with a series IX automated materials testing system in accordance with ASTM D 638. For tensile tests, the crosshead speed was $5 \mathrm{~mm} / \mathrm{min}$ and preparation of samples in dog bone shape.

\section{Results and Discussion}

\subsection{Characterization}

\subsubsection{FT-IR Spectra}

The IR spectra of PP,PPW and TPP before and after the exposure were recorded as seen Fig. 1. For the infrared spectrum of PP, there are beaks near 2976, 1460, and $1380 \mathrm{~cm}^{-1}$. In addition, medium intensity beaks are observed near 1155 and $970 \mathrm{~cm}^{-1}$, attributable to the asymmetry stretching vibration of $\mathrm{CH}_{3}\left(1460 \mathrm{~cm}^{-1}\right)$, the symmetry bending vibration of $\mathrm{CH}_{3}\left(1380 \mathrm{~cm}^{-1}\right)$, vibration of the rocking of $\mathrm{CH}_{3} \&-\mathrm{CH}_{2}$ and the stretching of $\mathrm{CH}_{-}-\mathrm{CH}_{2}$ \& $\mathrm{CH}-\mathrm{CH}_{3}\left(1155,970\right.$ and $\left.841 \mathrm{~cm}^{-1}\right)$ (Socrates 2001;p. 268-169 and Othman et al. 2006). When comparing the IR spectra of PP with its composites, no obvious changes between the spectra of PPW and PP. In the case of TPP, there are several shifting obtained for some beaks. All the regions of spectra listed in Table 4.

After 6 months of exposure, various chemical reaction take place which result in the change of FT-IR spectra . Several peaks in the carbonyl region (1684-1725) $\mathrm{cm}^{-1}$ in spectrum of PP, which are attributed to carboxylic acid and conjugated ketone, respectively. In addition, a beak at $1635 \mathrm{~cm}^{-1}$, which is attributed to vinyl group. For PPW and TPP spectra, It is clear that there are beaks appear at the carbonyl region (1722) $\mathrm{cm}^{-1}$ of PPW and (1726) $\mathrm{cm}^{-1}$ of TPP which are attributed to carboxylic acid. In the hydroxyl region, the IR spectra of both composites have shown weak and broad peak in the ranges of (3400-3460) $\mathrm{cm}^{-1}$ (Tidjani 2000, Tidjani \& Arnaud 1995).

The presence of carbonyl, acid and ketone species acknowledges the presence oxidation products in the weathered samples (Leong et al. 2004). The little changes during the natural photo-oxidation of PPW and TPP indicate that these samples more stable than PP. It can say that the additives materials of PP in the composites Played positive roles on the stability of PP. On the other hand, the difference in intensity in the carbonyl region of PPW and TPP spectra indicates that the TPP sample was better than PPW to resist photo-oxidation. This means that the role played by the talc was more positive.

\subsubsection{Scanning Electron Microscope (SEM)}

Figs 2, 3, 4 and 5 show surfaces before and after exposure. As seen in Fig. 2 Which shows the surface of samples before exposure. The surface looks smooth relatively. After 2 months of exposure, the surfaces became rough as seen in Fig. 3, this could means that it is still at the initial stages of degradation by natural photo-oxidation.

From Fig. 4 which shows PP and its composites after 4 months of exposure, it is clear that there are cracks and unidirectional micro fissures could be seen on the surface of degraded samples which increased strongly after 6 months and some particles can be observed as seen in Fig 5, which may be caused by the fracture of large amount of fragments from surface. All of this surface damages form spontaneously during UV exposure as a result of the surface layers, which lead to shrinkage (Rabello \& White 1997). Although surface cracks are evident in all samples after being weathered for 6 months, the severity of the cracks varies from one another where the least damage done by weathering is on TPP that contain talc particles as a filler of PP. This results in lower damage of PP matrix comparing with PPW and PP.

\subsection{Mechanical Testing}

From Fig. 6 which shows the tensile stress at break as a function of Weathering Time (month), it is clear that the initial stress at break (before exposure) of TPP is the highest comparing to PP and PPW. This indicates that the polymer became harder. After exposure, the stress at break decreases of all samples over a period of 6 months due to the effects of polymer degradation where could be attributed to the natural photo-oxidation of the polymer, which result in chain under UV exposure. This leads to physical deterioration of the polymer ( Tidjani 1997). On the other hand, The TPP sample seemed to have better retention of tensile strength compared to another samples, it can thus be hypothesize that talc, which is platy in natural, would act as the reinforcing filler in the composites.

Fig. 7 shows the elongation at break Versus Weathering Time (month). Remarkably, the initial elongation at break value of the PP sample (before exposure) is much higher than that of another sample. This indicates that the composites is more brittle especially, TPP which has the lowest value of elongation at break. This is a consequence of the much lower ductility of the composites resulting from the presence of the additives. After exposure, although initially the deformability of PP itself is the highest compared to other samples, the effects of weathering caused its elongation at break to decline to a point below that of composites after 2 months of weathering time. This means 
that the PP becomes very brittle after short exposure times. This is a consequence of the large drop in molecular weight associated with degradation. Regarding PPW which seemed more brittle comparing to PP before exposure, showed similar behavior of PP sample after exposure especially after 4 months of weathering time. Decline in elongation at break with increasing in the weathering time of PP and PPW, this is caused by extensive chain scission in the samples, causing the breakdown of tie chain molecules and entanglements, which are especially detrimental to the ductility of the polymer. On the contrary, TPP remains constant in the first 2 months of weathering. After this period of weathering, TPP sample shows little change then keep remaining constant after 6 months. This can be explained, it is possible that the interfacial adhesion can be enhanced by degradation following formation of the carbonyl group in PP which are more compatible with talc particle. However, when comparing to their resistance of change during exposure, it can be very obvious that the TPP shows more resistance and the change in elongation at break versus exposure time decreases slightly where seemed more stability of degradation than another samples as a result of the presence of talc particles.

From Fig. 8 which shows the young's modulus versus weathering Time (month), it is clear that PPW before weathering seemed the softest where the values of young's modulus are the least compared to other samples while the TPP composite seemed the most rigid and the PP has an average behavior between them. Although, PPW is still the softest after weathering, but the rigidity of it increases gradually with increasing exposure time while for the other two samples, the rigidity decreases with increasing exposure time then increases after 4 months of exposure significantly especially for TPP and this result indicates that all samples became more rigid. This could be attributed to the surface cracks that have formed the polymer. However, longer exposure times lead to the development of more and more surface cracks which in turn allow degradation process to take place, which causes a ductile to brittle transition of the polymer, thus rendering it to lose its soft.

\section{Conclusion}

$\mathrm{PP}$ and its composites were prepared and the effect of natural weathering on morphology and mechanical properties of them were investigated. From the above results, it can be concluded:

- As evidenced from FT-IR, the natural weathering exposure of PP and its composites are caused degradation judging by the formation of photo-oxidation products.

- From SEM analyses on the surface, the photo- oxidation of materials begins from the surface and then develops along the depth gradually.

- Several changes observed in mechanical properties as a result of degradation of polymer.

- The results showed that the talc play a role in improving the stability of PP slightly, but the relationship between shape, size, the treatment of the talc surface and preparation method of composites and stability of polymer needs further research.

\section{References}

Abu-Sharkh, B. F., \& Hamid, H. (2004). Degradation study of date palm fiber/polypropylene composites in natural and artificial weathering: mechanical and thermal analysis. Polymer Degradation and Stability, 85, 3, 967-973

Al-Madfa, H., Mohamed, Z., \& Kassem, M.E. (1998). Weather ageing characterization of the mechanical properties of the low density polyethylene. Polymer Degradation and Stability, 62, 105-9.

Azuma, Y., Takeda, H., Watanabe, S., \& Nakatani, H. (2009). Outdoor and accelerated weathering tests for polypropylene and polypropylene/talc composites: A comparative study of their weathering behavior. Polymer Degradation and Stability, 94, 2267-2274.

Dence, M., Musil, V., \& Smit I. (2005). Polypropylene/talc/SEBS(SEBS-g-MA). Composites. Part A, Applied Science Manufacturing, 36, 1282-90.

Leong, Y.W., Abu Bakar, M.B., Mohd Ishak, Z.A., \& Ariffin, A. (2004). Characterization of talc/calcium carbonate filled polypropylene hybrid composites weathered in a natural environment. Polymer Degradation and Stability, 83, 411-422.

Naiki, M., Fukui, Y., Matsumura, T., Nomura, T., \& Matsuda, M. (2001). The effect of talc on the crystallization of isotactic polypropylene. Journal of Applied Polymer Science, 79,1693-703.

Obata,Y., Sumitomo, T., Masuda, M., \& Nomura, T. (2001). The effect of talc on the crystal orientation in polypropylene/ethylene-propylene rubber/talc polymer blends in injection molding. Polymer Engineering and Science, 41, 408, 16. 
Othman, N., Ismail, H., \& Mariatti, M. (2006). Effect of compatibilisers on mechanical and thermal properties of bentonite filled polypropylene composites. Polymer Degradation and Stability, 91,1761-74.

Rabello, M.S., \& White, J.R. (1997). Photodegradation of polypropylene containing a nucleating agent. Journal of Applied polymer Science, 64,2505-17.

Socrates, G. (2001). Infrared and Raman Characteristic Group Frequencies. (3rd ed.) Chichester: John Wiley \& Sons Ltd, (Chapter 21; page 268-269).

Tidjani, A. (1997). Photooxidation of polypropylene under natural and accelerated weathering conditions. Journal of Applied Polymer Science, 64, 2497- 503.

Tidjani, A. (2000). Comparison of formation of oxidation products during photo-oxidation of linear low density polyethylene under different natural and accelerated weathering condition. Polymer Degradation and Stability, 68,465-9.

Tidjani, A., \& Arnaud, R. (1995). Formation of treeing figures during the photooxidation of polyolefins. Polymer, $36,2841-4$.

Xue, Y., Veazie, D.R., Glinsey, C., Horstemeyer, M.F., \& Rowell, R.M. (2007). Environmental effects on the mechanical and thermomechanical properties of aspen fiber-polypropylene composites. Composites Part B:

Engineering, 38, 2, 152-158.

Yang, R., Yu, J., Liu, Y., Wang, K. (2005). Effects of inorganic fillers on the natural photo-oxidation of high-density polyethylene. Polymer Degradation and Stability, 88, 2, 333-340.

[Online] Available: http://en.wikipedia.org/wiki/Riyadh\#Climate.

Table 1. Product data for PP 520L

\begin{tabular}{|l|l|l|l|}
\hline Property & Unit & Value & Test Method \\
\hline Melt Flow Rate $\left(216 \mathrm{Kg} \& 230^{\circ} \mathrm{C}\right)$ & $\mathrm{g} / 10 \mathrm{~min}$ & 10 & ASTMD-1238 \\
\hline Tensile Strength @ Yield & $\mathrm{MPa}$ & 35 & ASTMD-638 \\
\hline Tensile Elongation @ Yield & $\%$ & 10 & ASTMD-638 \\
\hline Flexural Modulus (1\%SECANT) & $\mathrm{MPa}$ & 1600 & ASTMD-790A \\
\hline Notched Izod Impact Strength @ $23^{\circ} \mathrm{C}$ & $\mathrm{J} / \mathrm{m}$ & 23 & ASTMD-256 \\
\hline Heat Distortion Temperature @ $455 \mathrm{KPa}$ & ${ }^{\circ} \mathrm{C}$ & 105 & ASTMD-648 \\
\hline Victa Softing Temperature & ${ }^{\circ} \mathrm{C}$ & 155 & ASTMD-1525B \\
\hline Hardness & Rockwell & $102 \mathrm{R}$ & ASTMD-785 \\
\hline
\end{tabular}

Table 2. Molding conditions

\begin{tabular}{|l|l|l|l|}
\hline Injection Pressure & $500 \mathrm{~Pa}$ & Temperature Zone 1 & $180^{\circ} \mathrm{C}$ \\
\hline Holding Pressure & $500 \mathrm{~Pa}$ & Temperature Zone 2 & $20{ }^{\circ} \mathrm{C}$ \\
\hline Cooling Time & $10 \mathrm{~s}$ & Temperature Zone 3 & $215^{\circ} \mathrm{C}$ \\
\hline Holding Time & $10 \mathrm{~s}$ & Nozzle Temperature & $235^{\circ} \mathrm{C}$ \\
\hline
\end{tabular}


Table 3. Details of the climate condition in Riyadh city

\begin{tabular}{|c|c|c|c|c|c|c|}
\hline Month & Apr & May & Jun & Jul & Aug & Sep \\
\hline Record high ${ }^{\circ} \mathrm{C}$ & 42.0 & 45.1 & 47.1 & 48.0 & 47.8 & 44.5 \\
\hline Average high ${ }^{\circ} \mathrm{C}$ & 33.3 & 39.1 & 42.4 & 43.5 & 43.2 & 40.3 \\
\hline Daily mean ${ }^{\circ} \mathrm{C}$ & 26.8 & 32.7 & 35.4 & 36.6 & 36.3 & 33.2 \\
\hline Record low ${ }^{\circ} \mathrm{C}$ & 11.0 & 18.0 & 16.0 & 23.6 & 22.7 & 16.1 \\
\hline Average low ${ }^{\circ} \mathrm{C}$ & 20.3 & 25.7 & 27.6 & 29.1 & 28.8 & 25.7 \\
\hline Rainfall mm & 22.3 & 4.6 & 0.0 & 0.0 & 0.2 & 0.0 \\
\hline Humidity \% & 28 & 17 & 11 & 10 & 12 & 14 \\
\hline
\end{tabular}

Table 4. The regions of spectra of PP, PPW and TPP before weathering

\begin{tabular}{|l|l|l|l|}
\hline PP & PPW & TPP & Comment \\
\hline 2976 & 2975 & 2975 & \\
\hline 1460 & 1448 & 1446 & Shifting (PPW,TPP) \\
\hline 1380 & 1380 & 1380 & \\
\hline 1155 & 1155 & 1160 & Shifting (TPP) \\
\hline 970 & 970 & 979 & Shifting (TPP) \\
\hline 841 & 841 & 841 & These beaks attributed to OH group of \\
\hline & & 3668 (stretching) & \begin{tabular}{l} 
octahedral layers of the talc surface \\
\hline
\end{tabular}
\end{tabular}



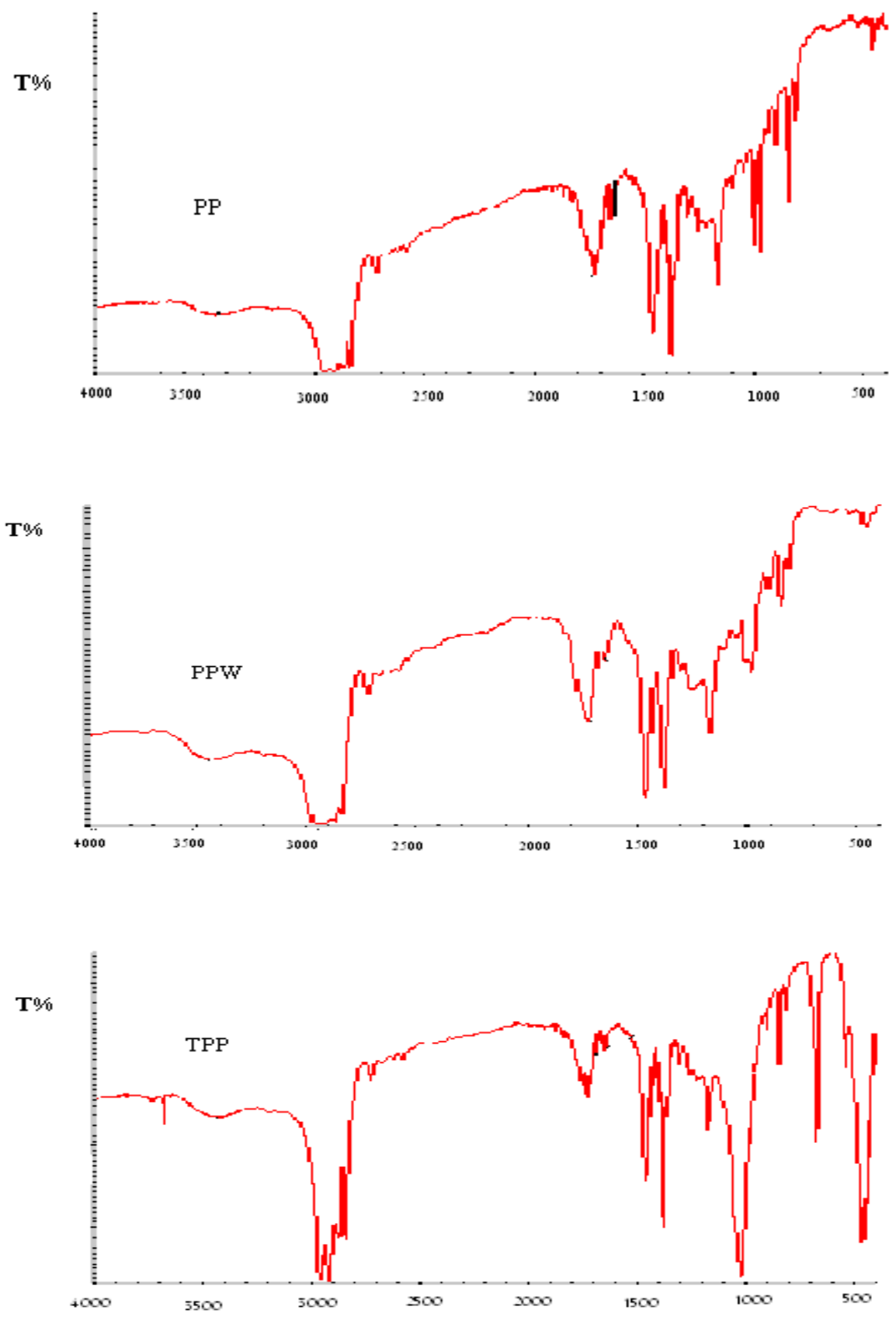

Wavenumber $\left(\mathrm{cm}^{-1}\right)$

Figure 1. PP, PPW and TPP before exposure 

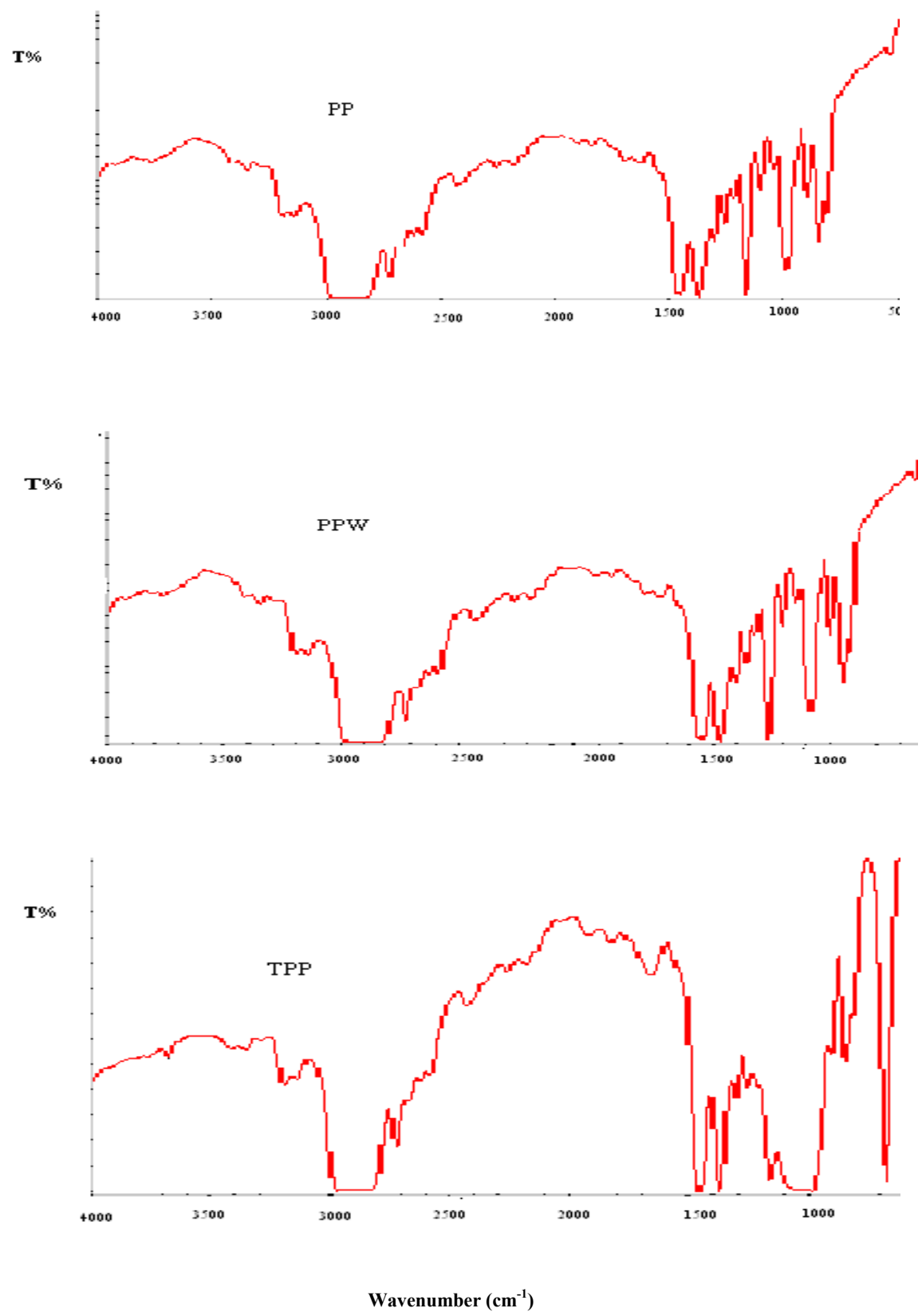

Figure 1. (Continued); after 6 month from exposure 

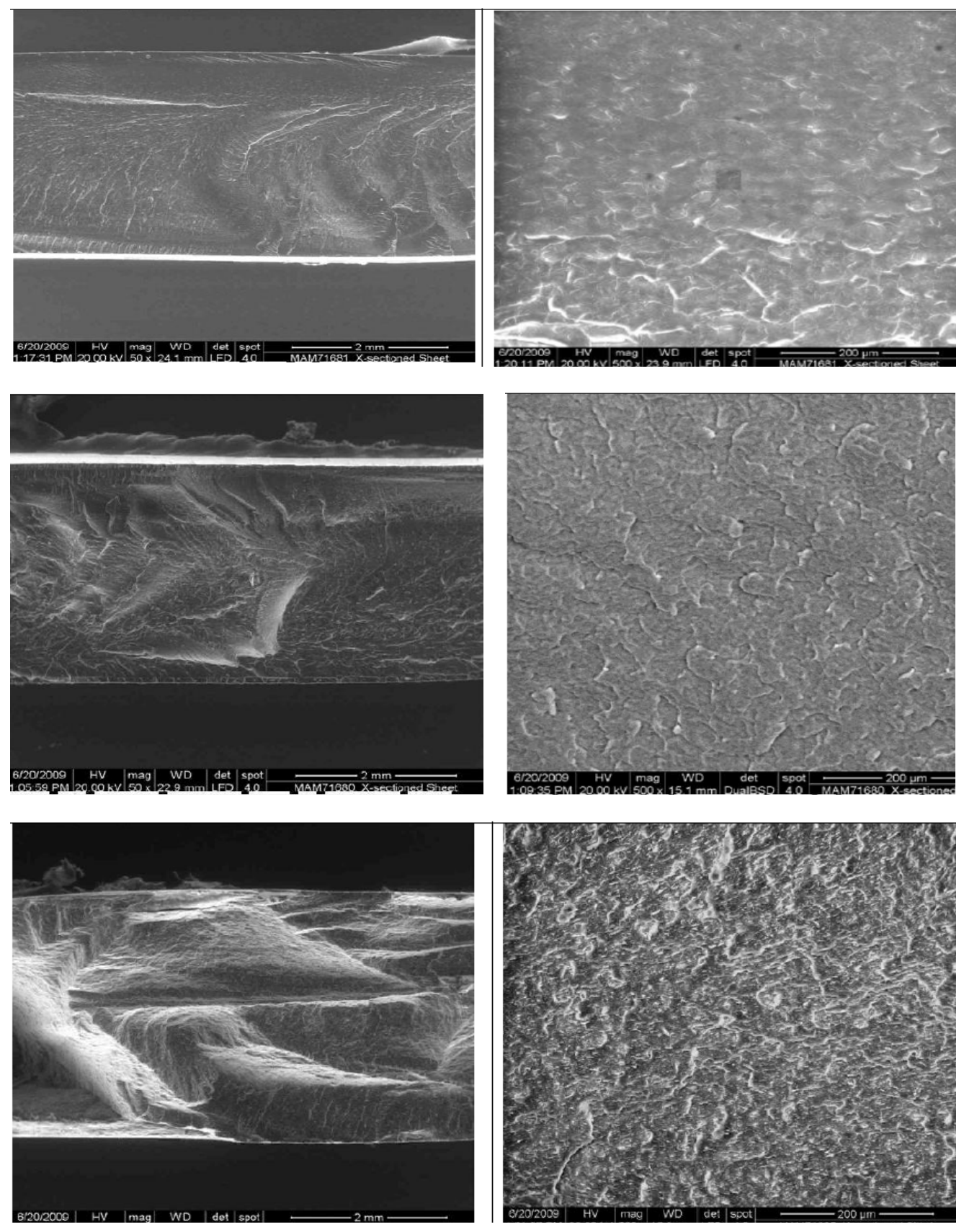

Figure 2. Surface aspects before exposure

(above) PP, (middle) PPW and (below) TPP. 

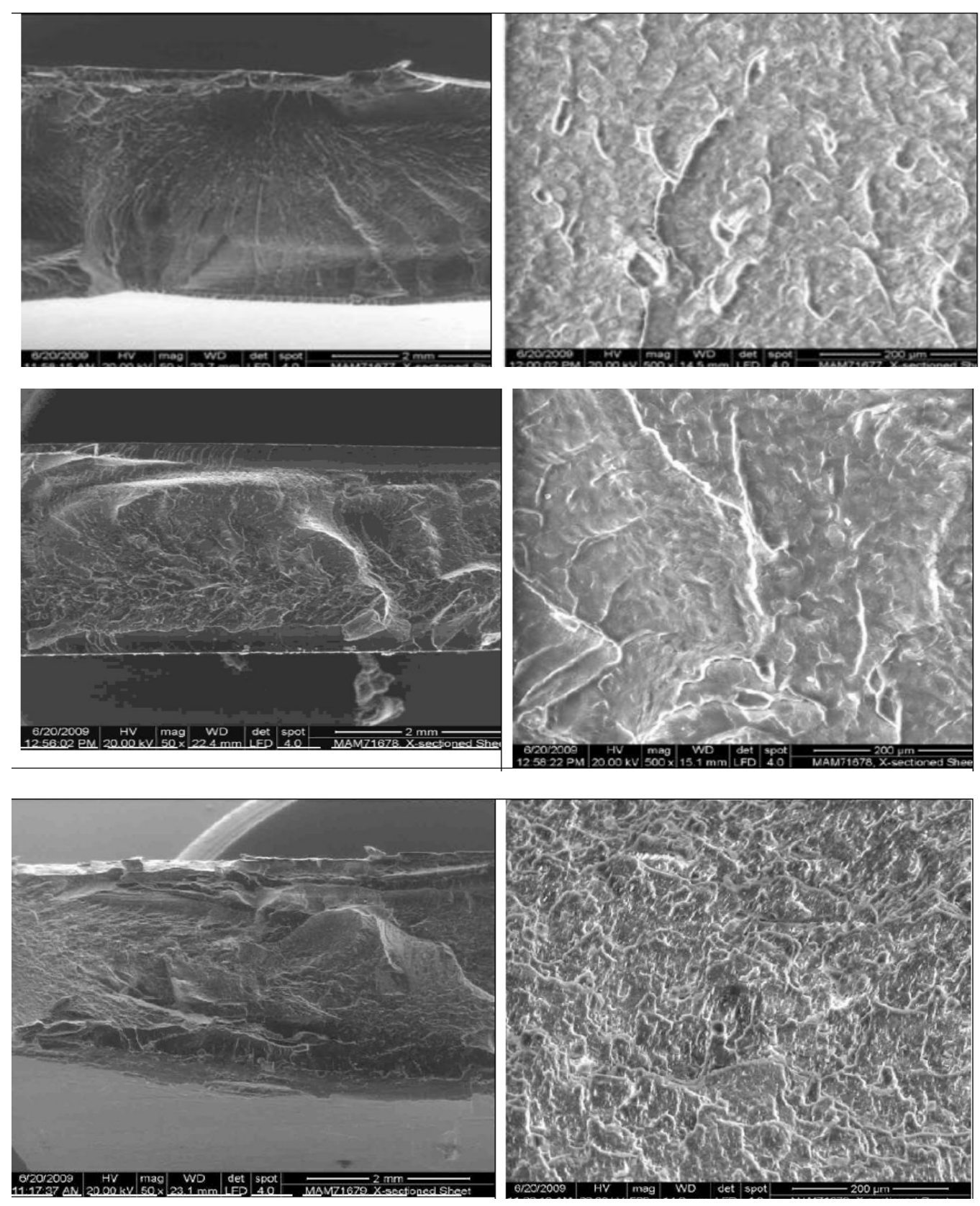

Figure 3. Surface aspects after 2 months of exposure

(above) PP, (middle) PPW and (below) TPP. 

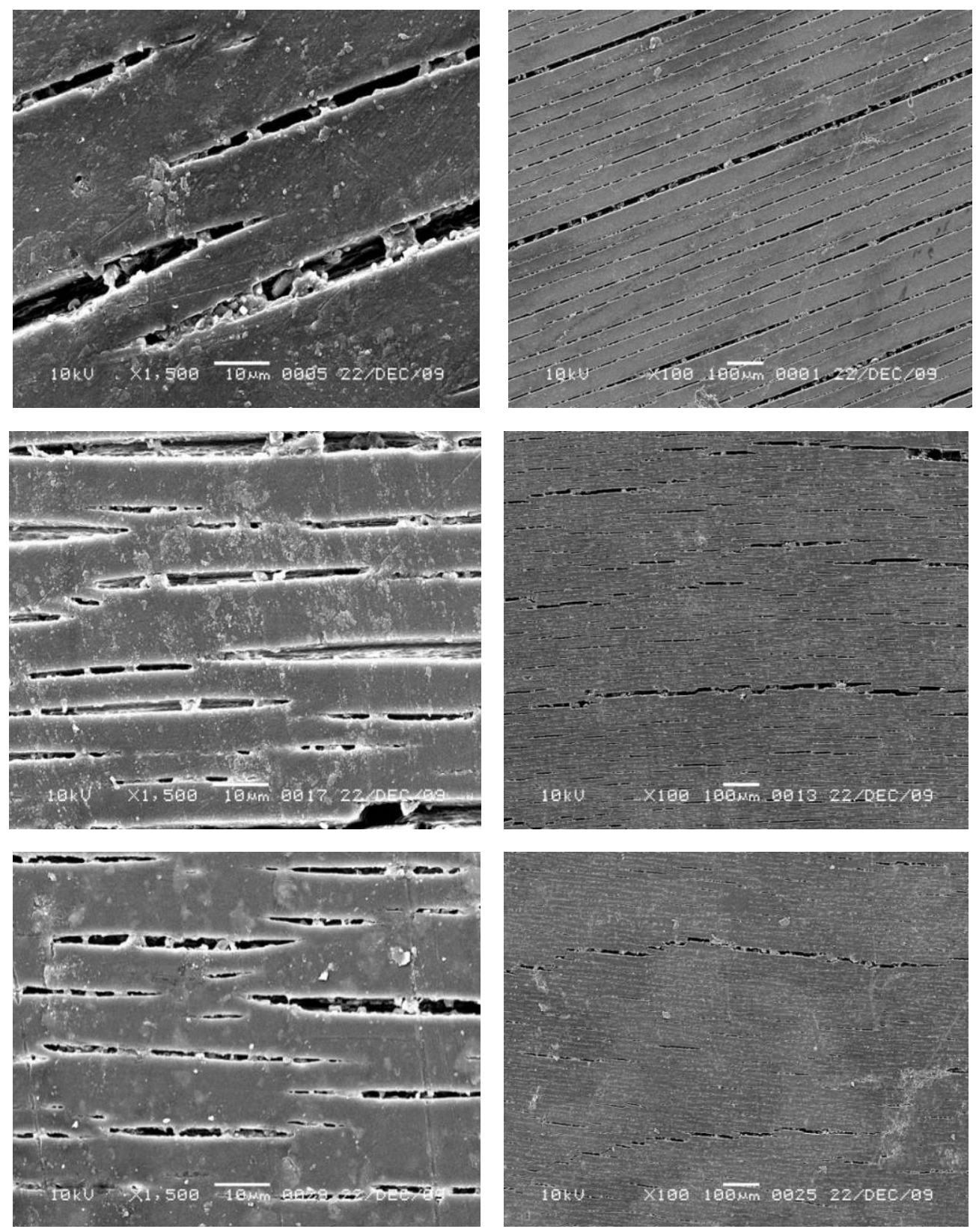

Figure 4. Surface aspects after 4 months of exposure

(above) PP, (middle) PPW and (below) TPP. 

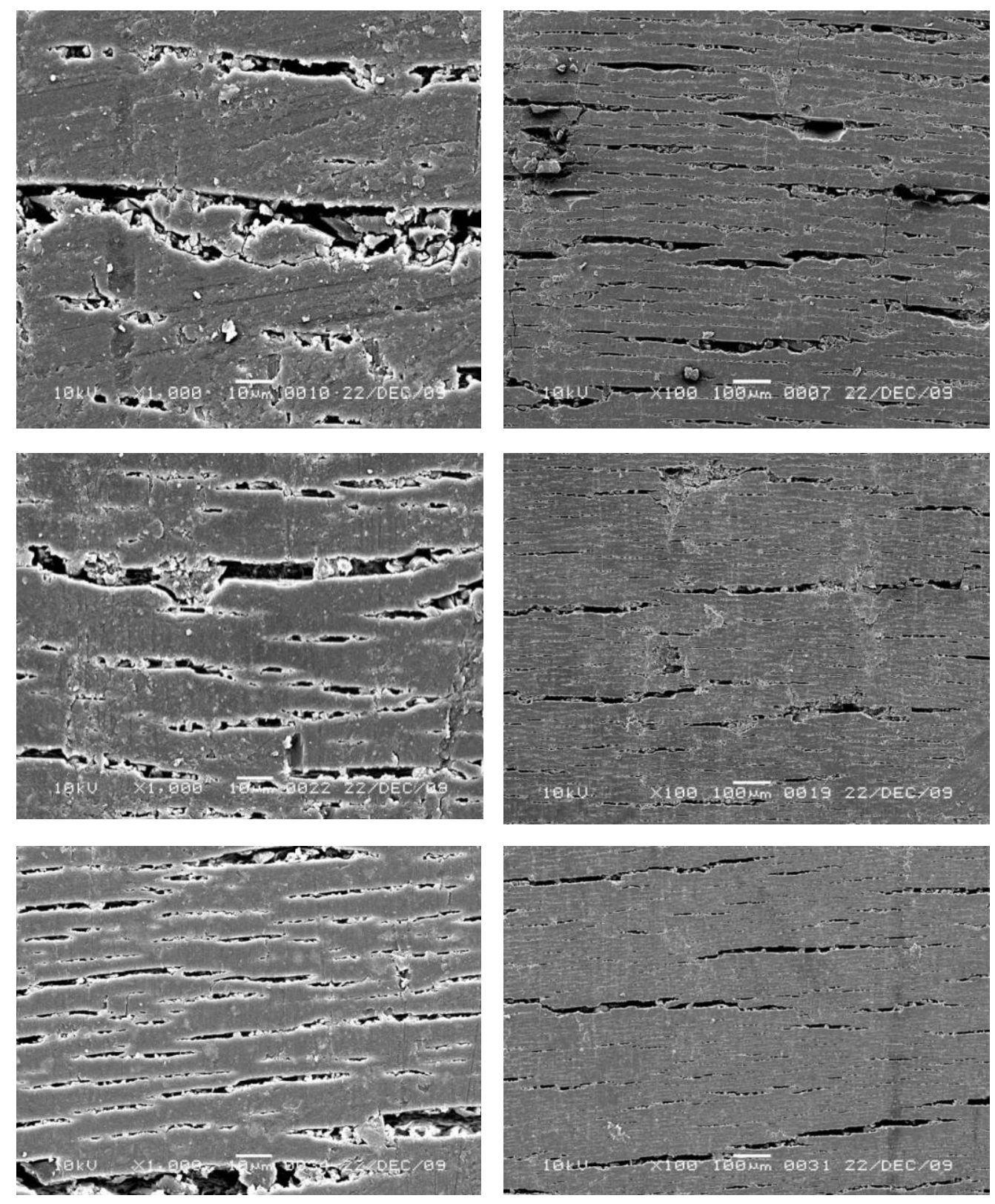

Figure 5. Surface aspects after 6 months of exposure

(above) PP, (middle) PPW and (below) TPP. 


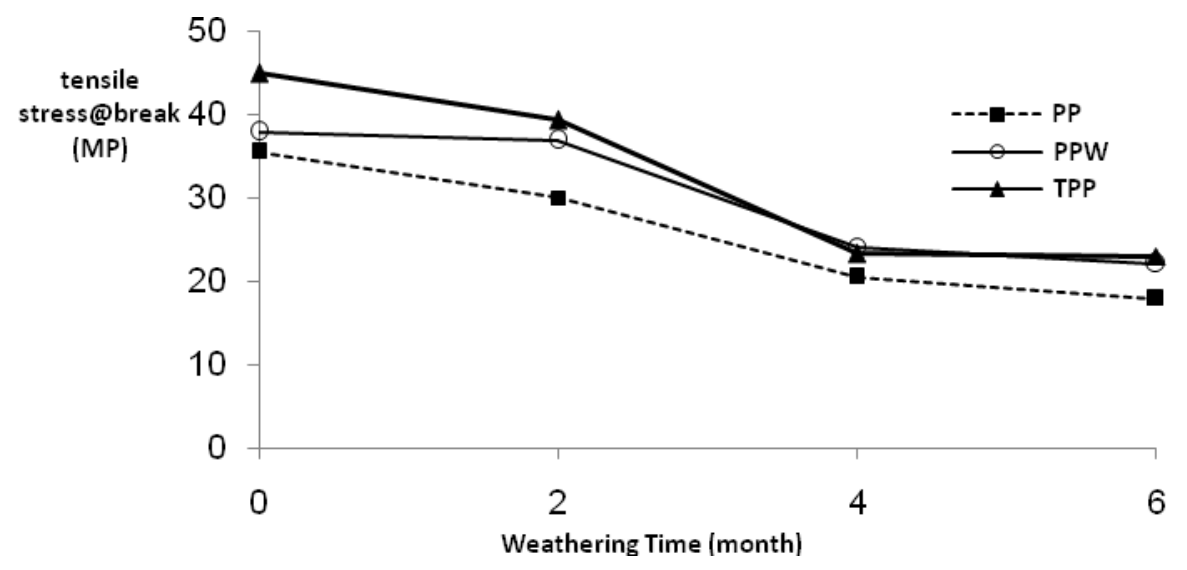

Figure 6. Tensile stress at break as a function of Weathering Time (month)

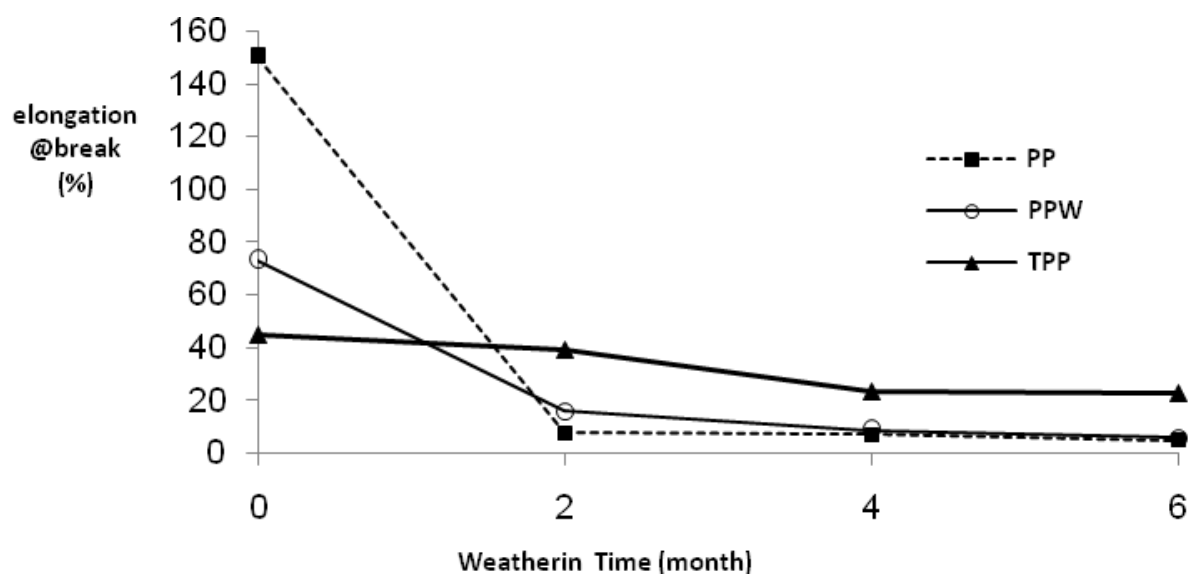

Figure 7. Elongation at break as a function of Weathering Time (month)

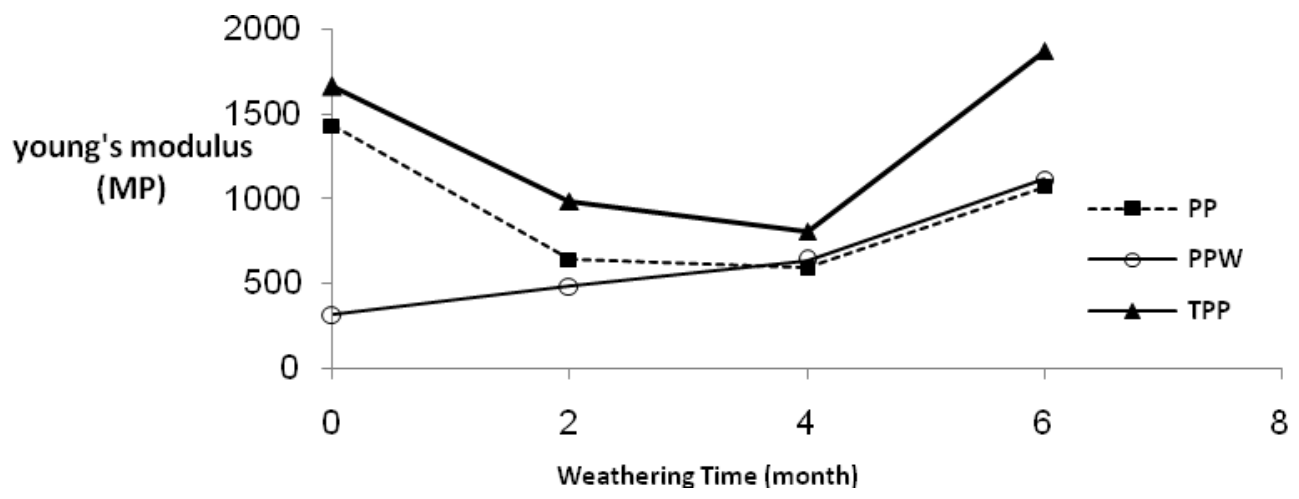

Figure 8. Young's modulus as a function of Weathering Time (month) 